\title{
ALGUNS MOTIVOS PARA ENSINAR GÊNERO E SEXUALIDADE ÀS CRIANÇAS DESDE A EDUCAÇÃO INFANTIL
}

\author{
Anderson Ferrari \\ Gabriela Silveira Meireles
}

\section{Resumo}

Tomando como inspiração a fala de professoras nas nossas ações de formação nas escolas, vamos problematizar, neste artigo, as potencialidades e os desafios presentes no trabalho com as relações de gênero e sexualidade na educação infantil. $O$ nosso objetivo foi desenvolver reflexões sobre os sentidos e significados das ações de "ensinar", "aprender" e "educar", dentro de uma perspectiva de educação para as relações de gênero e sexualidade nas escolas. Para isso, nos baseamos nas abordagens teórico-metodológicas feministas, pós-estruturalistas e foucaultianas. Todas elas nos convidam a pensar os processos de constituição dos sujeitos, como resultado das relações saber-poder, incitando-nos a uma revisão de nossas práticas enquanto professoras e professores. Pudemos perceber a necessidade de uma compreensão mais ampla dos conceitos de gênero e sexualidade, bem como da articulação entre eles, o que facilitaria a eliminação de algumas barreiras para abordá-los sem medo.

Palavras-chave: gênero; sexualidade; educação infantil.

\section{SOME REASONS FOR TEACHING GENDER AND SEXUALITY TO CHILDREN SINCE CHILDHOOD EDUCATION}

\begin{abstract}
Taking as inspiration the speech of teachers in our training actions in schools, we will discuss, in this article, the potentialities and challenges present in the work with the relations of gender and sexuality in early childhood education. Our objective was to develop reflections on the senses and meanings of the actions of "teaching", "learning" and "educating", within an education perspective for gender and sexuality relations in schools. For this, we are based on feminist, post-structuralist and foucaultian theoretical-methodological approaches. All of them invite us to think about the subjects' constitution processes, as a result of the knowledge-power relations, inciting us to review our practices as teachers. We could see the need for a broader understanding of the concepts of gender and sexuality, as well as the articulation between them, which would facilitate the elimination of some barriers to address them without fear.
\end{abstract}

Keywords: gender; sexuality; early childhood education.

\section{ALGUNAS RAZONES PARA ENSEÑAR GÉNERO Y SEXUALIDAD A LOS NIÑOS DESDE LA EDUCACIÓN INFANTIL}

Resumen

Tomando como inspiración el discurso de los docentes en nuestras acciones de capacitación en las escuelas, problematizaremos, en este artículo, las potencialidades y desafíos presentes en el trabajo con las relaciones de género y sexualidad en la educación infantil. Nuestro objetivo fue desarrollar reflexiones sobre los sentidos y los significados de las acciones de "enseñanza", "aprendizaje" y "educación", dentro de una perspectiva educativa para las relaciones de género y sexualidad en las escuelas. Para esto, nos basamos en enfoques teórico-metodológicos feministas, postestructuralistas y foucaultianos. Todos ellos nos invitan a pensar en los procesos de constitución de las asignaturas, como resultado de las relaciones conocimientopoder, incitándonos a revisar nuestras prácticas como docentes. Podríamos ver la necesidad de una 
comprensión más amplia de los conceptos de género y sexualidad, así como la articulación entre ellos, lo que facilitaría la eliminación de algunas barreras para abordarlos sin temor.

Palabras clave: género; sexualidad; educación de la primera infancia.

\section{INTRODUÇÃO}

O título deste artigo anuncia uma intenção, de maneira que podemos afirmar que este artigo tem como objetivo desenvolver argumentos que sustentem as práticas pedagógicas na educação infantil voltadas à educação para as relações de gênero e sexualidade. Intenção que se desdobra numa pretensão: o verbo "ensinar", que traz junto de si um outro verbo, uma outra intenção ou pretensão: “aprender”. Se há motivos para ensinar, também podemos supor que há motivos para aprender sobre as relações de gênero e sexualidade, o que nos liga a um entendimento de gênero como construção, algo que se "ensina" e se "aprende", como "um mecanismo através do qual se produzem e se naturalizam as noções de masculino e de feminino" (BUTLER, 2006, p. 70); como um "ideal regulatório" que não somente cria a norma, mas que produz, regula e normaliza os corpos que governa (FOUCAULT, 1988).

Ao mesmo tempo em que evidenciamos o objetivo voltado para o propósito de "ensinar" e "aprender", também afirmamos que "há motivos para isso". Defender que há necessidades para ensinar, discutir, problematizar e, assim, sustentar as práticas pedagógicas na educação infantil vincula nossas intenções à formação de professoras e professores, no que diz respeito ao trabalho com as relações de gênero e sexualidade nas escolas. Intenções que são desejos: desejo de que aprendam para que desejem ensinar.

No entanto, para além da preocupação em elencar motivos que justifiquem o trabalho com as relações de gênero e sexualidade na educação infantil, vamos colocar sob escrutínio os jogos de saber-poder que organizam o pensamento e as atitudes diante das possibilidades dessas relações entre ensinar e aprender. Assim, queremos dizer que ensinar ou não gênero e sexualidade na educação infantil é uma ação que está ligada aos jogos de força e de poder que organizam as formas de conhecer, já que as maneiras de "ensinar e aprender" são investimentos nos sujeitos, entendidos como resultado de discursos, atravessados por relações de poder e frutos da ação dos outros (FOUCAULT, 1988).

Nosso interesse por essa temática e o que sustenta este texto propositivo é resultado de um movimento paradoxal que nos convoca à ação, necessária na atualidade. Por um lado, presenciamos um insistente movimento de ataques às escolas, de acusação e perseguição às professoras e aos professores que incluem as discussões de gênero e sexualidade nos seus planos de curso, além das tentativas de retirada desses temas dos documentos curriculares oficiais. Atitudes essas que são sustentadas sob o argumento de que essas questões são de foro íntimo, cabendo às famílias esse processo de educação dos sujeitos, ancorados em fundamentos religiosos e conservadores que insistem num entendimento de gênero e sexualidade como algo natural, ligado à essência dos sujeitos e à absolutização da Biologia.

Por outro lado, também vivenciamos um crescimento dos grupos de pesquisa, uma ampliação das discussões e produções de conhecimento nas universidades públicas laicas, através de congressos e seminários nacionais e internacionais, de revistas e dossiês que divulgam a diversidade e a riqueza das pesquisas na pós-graduação, a organização e a luta dos grupos LGBTTTQI pela igualdade de direitos, sobretudo o direito à existência, assim como pela democratização e pelo combate ao preconceito, à discriminação e ao extermínio de pessoas que fogem aos enquadramentos dos gêneros e das sexualidades. Um movimento que, na contramão do anterior, defende um entendimento de gênero e sexualidade ancorado nas perspectivas feministas, 
pós-estruturalistas e queer, como construção e como performatividade, que "deve ser entendida não como um 'ato' singular ou deliberado, mas como uma prática reiterativa e citacional por meio do qual o discurso produz os efeitos daquilo que nomeia” (BUTLER, 2019, p. 16).

Os dois movimentos atuais reiteram, pois, que gênero e sexualidade são conceitos em disputa. Mais do que isso, são dois movimentos que tomam o campo da educação como fundamental nesta batalha pela constituição dos sujeitos, por aquilo que aprendem, demostrando que são movimentos que confrontam formas de ensinar para definir formas de saber, ser e estar no mundo. Movimentos que estão presentes no cotidiano de professoras e de professores, que vêm à tona quando vamos às escolas e somos chamados para alguma ação de formação. Para além disso, esses dois movimentos estão servindo como justificativas para acolher ou rechaçar a discussão, alimentando, ao mesmo tempo, o medo e o enfrentamento, a vigilância e a resistência, a recusa e a vontade de trabalhar.

Nesse jogo de poder, alinhamo-nos pela defesa das relações de gênero e sexualidade como uma construção necessária no campo da educação. Esse posicionamento é resultado de nossas pesquisas e ações na formação docente, trazendo para a discussão formas de ensinar e aprender capazes de problematizar algumas concepções preconceituosas, constantemente divulgadas, que têm sustentado essa série de movimentos políticos e educacionais que tentam bloquear a abordagem dessas temáticas nas escolas brasileiras. Pretendemos, assim, "rejeitar um determinismo biológico implícito", que comumente ignora "o caráter fundamentalmente social" (SCOTT, 1995, p. 72) das distinções de gênero, pautado unicamente no sexo ou na diferença sexual. Além disso, afirmamos a necessidade de buscar desconstruir quaisquer afirmações generalizadas a respeito do que é ser homem ou mulher, menino ou menina (LOURO, 1997).

Assumimos, neste artigo, uma concepção de gênero como uma construção relacional, o que significa dizer que são as relações entre os gêneros e, no interior deles, que vão constituindo mulheres e homens como diferentes, de maneira que compreendemos aquilo que se supõe ser natural - as diferenças ou desigualdades de gênero - como algo que foi construído social e culturalmente, em conformidade com alguns padrões estabelecidos e que precisam, com urgência, de ser questionados, refeitos, desconstruídos (SCOTT', 1995). Seguindo a linha de análise de Michel Foucault, estamos tomando a sexualidade como um dispositivo histórico, de maneira que não é possível falar de sexualidade sem pensá-la como ligada à história dos discursos.

Para o desenvolvimento deste texto, vamos focar nossas problematizações tomando por base as construções teóricas dos Estudos de Gênero, dos Estudos Feministas e dos Estudos Foucaultianos. Partimos da premissa de que há um entendimento de gênero que acaba distorcendo a necessidade de as crianças serem educadas desde cedo para o gênero e para a sexualidade. Em seguida, concentraremos na ideia de que, mesmo sem admitir, há uma forte presença dos ensinamentos de gênero e de sexualidade na vida das crianças (mesmo antes do seu nascimento). Para desenvolver essas duas partes do artigo, vamos acionar algumas falas que emergem em nossas ações de formação nas escolas e nas falas de professoras da educação infantil, que nos fazem pensar sobre a necessidade de que as professoras e os professores "aprendam para ensinar", ou seja, tomem contato com as concepções de gênero e de sexualidade elaboradas cientificamente, para quem possam ressignificar as suas práticas. Foi isso que nos inspirou a produzir este texto.

\section{POR QUE EDUCAR AS CRIANÇAS PARA AS RELAÇÕES DE GÊNERO NA EDUCAÇÃO INFANTIL?}

Educação infantil e relações de gênero e sexualidade são duas áreas de conhecimento que nem sempre caminham juntas, embora tenhamos um grupo de pesquisadoras que, há algum tempo, vêm se dedicando a estabelecer e a propor essa relação, como, por exemplo, Jane Felipe (2000), 
Daniela Finco (2003), Cláudia Maria Ribeiro (2012), Constantina Xavier Filha (2014), dentre outras. Isso porque a concepção de infância e de educação para as infâncias também traz entendimentos de gênero e sexualidade, sobretudo para essa fase da vida, como limitados à ideia de sexo, curiosidade, exploração e contato com o corpo, algo que merece ser estudado e não interditado, vigiado e controlado. Questionando a "hipótese repressiva", Michel Foucault (1988) vai rechaçar esse poder repressivo como o que tenha vigorado desde o século XVIII, para afirmar que, ao contrário de uma negação em falar, fomos invadidos por uma "vontade de saber" capaz de dar lugar a uma proliferação discursiva em torno do corpo, dos desejos, das ações, dos pensamentos, dos ritos e dos espaços legítimos em relação à sexualidade.

Defendemos que a sexualidade é um dispositivo mais amplo. Foucault vai nos alertar que reduzi-la "[...] à relação conjugal, com o perigo de projetá-la sobre as crianças na forma de desejo interdito, não pode dar conta desse dispositivo que é, no que se refere a tais sexualidades, menos princípio inibidor do que mecanismo incitador e multiplicador" (FOUCAULT, 1988, p. 46). Ainda somos herdeiros da separação relativa aos espaços em que se pode ou não falar, quando devemos falar, para quem são direcionados os discursos e, principalmente, quem está autorizado a tratar, falar, ensinar e educar para as relações de gênero e sexualidade. As escolas, as salas de aula, as professoras da educação infantil estão sob essas relações de saber-poder, que autorizam ou não, o investimento na problematização do que sabemos, do que trazemos para as escolas e as negociações com outros espaços e relações pessoais.

Tais situações causam medo, ansiedade, tensão, mas também um compromisso com o saber, com as possibilidades de ampliar os horizontes de meninas e meninos, de educar para outras relações de gênero, visões de mundo e um outro significado desses termos para as escolas e para o exercício da docência. Um exemplo desses jogos de saber-poder que estão nas escolas pode ser encontrado na fala de uma professora de educação infantil que, durante uma ação de formação na escola, nos conta uma situação vivida por ela:

Eu quero colocar uma situação que vivi, para saber como eu devo fazer, porque eu fiquei tensa. Eu estava na porta da minha sala recebendo os alunos, como sempre faço, e chega uma mãe com a filha pela mão. E aí aconteceu a seguinte situação:

- Olha só, tia, a Maria está pedindo um carrinho de presente de dia das crianças. Eu já falei com ela que não pode, que carrinho é brinquedo de menino, não é, tia? Diz para ela, tia, que carrinho é coisa de menino, que menina não pode ganhar carrinho de presente e nem brincar com brinquedos de meninos.

- Mãe, mas pode ser cor de rosa.

Trazer o que viveu para o debate junto às demais professoras e transformar em busca por saber são formas de socializar a experiência, que, em última análise, pode ser traduzida na pergunta por que educar as crianças para as relações de gênero na educação infantil? Essa situação, ao colocar a professora diante de uma relação de submissão a um conjunto discursivo pautado no sexismo, nos leva a afirmar que existem alguns motivos importantes para que essas temáticas sejam abordadas desde a educação infantil nas escolas, principalmente porque elas estão presentes nesse segmento, elas chegam pelos pais, pelas alunas e alunos, elas organizam as relações de meninas e meninos com o mundo, como possibilidades de existência. Mais do que isso, são situações que cobram da professora uma postura que aciona a sua formação, os seus saberes docentes, as relações sociais e culturais, não somente em torno do que entende como gênero, mas também sobre o que cabe à escola, à sua ação enquanto professora nas negociações com a família. 
De imediato, podemos responder que há necessidade de trabalhar as relações de gênero e sexualidade na educação infantil, porque elas são trazidas para as escolas, independente da vontade das professoras, como a situação demonstra. A professora inicia sua fala dizendo da tensão que a situação causa. Por um lado, uma tensão criada pela cobrança da mãe por um discurso que confirme o seu entendimento de gênero como uma fronteira entre meninas e meninos, uma fronteira estabelecida nos brinquedos e no que cabe a meninas e meninos, que, segundo ela, não deve ser ultrapassada. O que a professora nos coloca é uma questão muito recorrente: Como fazer um trabalho com as relações de gênero e a sexualidade nos encontros e desencontros com o que as famílias ensinam? Há também uma outra tensão na resposta da criança: "mãe, mas pode ser cor de rosa".

A criança parece já ter incorporado essa fronteira entre os gêneros e negocia com isso, demonstrando que já aprendeu o jogo discursivo que afirma que a cor rosa é própria para meninas. Assim, se ter um carrinho não é possível, porque é brinquedo de menino, o argumento de que esse carrinho pode ser rosa parece demonstrar um aprendizado já incorporado pela menina em uma negociação para diminuir essa proibição. Ter um carrinho, brincar com carrinhos é a reivindicação da menina para ocupar outros espaços e formas de estar no mundo, o que entra em confronto com o que a mãe espera da filha. Já a tensão da professora parece se organizar em torno dessa reivindicação: Como propiciar outros espaços que ultrapassem as fronteiras dos gêneros e lidar com os medos em torno das sexualidades? Que medos organizam nossas interdições de meninas brincarem de carrinho? De quem é o medo? Da mãe ou da filha? Medos que misturam gênero com sexualidade. Quando meninas se afastam do que é tido como próprio de meninas, elas parecem se afastar também de uma certa ordem normativa que fixa o corpo, o sexo, o gênero e a sexualidade: nasceu num corpo identificado como do sexo feminino, será uma menina e heterossexual.

Essa situação foi o que nos motivou para a escrita deste artigo, sobretudo porque nos convida a colocar sob suspeita nossas formas de pensar e agir, aproximando-nos do sentido de problematização para Foucault (2006). Problematizar, para o autor, é uma metodologia de investigação, ligada à história do pensamento. Problematizar seria dar um passo atrás para transformar em problema de investigação algo que não nos chama atenção, um movimento que nos faz questionar nossas formas de pensar: Por que pensamos como pensamos? E, assim, interrogar nossas ações: Por que agimos da forma como agimos? Nossas formas de pensar e agir estão inscritas na história do pensamento. Existe uma história do pensamento que organiza nossas formas de pensar e agir.

O pensamento não é o que se presentifica em uma conduta e lhe dá sentido; é, sobretudo, aquilo que permite tomar uma distância em relação a essa maneira de fazer ou de reagir, e tomá-la como objeto de pensamento e interroga-la sobre seu sentido, suas condições e seus fins. O pensamento é liberdade em relação àquilo que se faz, o movimento pelo qual dele nos separamos, constituímo-lo como objeto e pensamo-lo como problema. (FOUCAULT, 2006, p. 231-232).

É esse convite de Foucault, de problematizar os sentidos, as condições e os fins da situação narrada pela professora que queremos tomar como motor para nossos argumentos em torno da defesa do trabalho com as relações de gênero e sexualidade na educação infantil. É nessa aposta no "pensamento como liberdade", seguindo as trilhas de Foucault (2006), que queremos problematizar a desigualdade histórica entre homens e mulheres, no que se refere aos direitos, às características e às atitudes, assim como colocar sob suspeita os enquadramentos que afetam as crianças no que se refere às suposições de que haveria cores, roupas e brincadeiras próprias para um ou outro gênero. 
Enfim, queremos questionar práticas pedagógicas excludentes que insistem em separar as meninas e os meninos para ocupar espaços ou realizar atividades diferenciadas.

Não queremos dizer, com isso, que o trabalho com as questões de gênero e sexualidade na educação infantil seja algo fácil de ser feito. Não é possível desconsiderar que as diferenças entre as escolas, de forma que essas diferenças vão dificultar ou facilitar as propostas. De qualquer modo, nossa defesa é o que trabalho não seja algo realizado de maneira individual, isolada, mas que seja resultado de uma discussão coletiva na escola, capaz de construir algo mais perene, conhecido e acolhido por toda escola, que faça parte do projeto pedagógico e de um sentido de educação. Por isso, trouxemos para o debate a situação narrada pela professora. Primeiro, porque ela surge a partir de uma ação de formação que gerou o convite para nossa presença junto ao coletivo de professoras discutindo, exatamente, as relações de gênero, sexualidade e educação. Depois, porque, ao narrar o que viveu, a professora compromete a escola a pensar junto, fortalecendo o seu trabalho, que deixa de ser uma resposta individual para se transformar num posicionamento da instituição. Por último, porque as experiências servem para que cada uma e um pense nas suas atitudes, nos seus valores e nos seus saberes diante do que é narrado para se posicionar. Compartilhar as experiências é uma forma de formação, já que serve para colocar em circulação nossas formas de saber, pensar e agir.

\section{RECONHECENDO A DESIGUALDADE HISTÓRICA ENTRE MULHERES E HOMENS}

O reconhecimento das desigualdades entre mulheres e homens é uma das condições de emergência da fala da mãe e da tentativa de interditar a solicitação da menina pelo carrinho. Mas esse reconhecimento não se basta, há a necessidade de que ele seja reforçado por outra autoridade, fazendo com que a mãe recorra à professora, reconhecendo, assim, a sua autoridade em proferir um discurso de interdição, que, no encontro com a sua fala, seria capaz de afastar o desejo da menina e direcioná-lo para outro objeto, construindo, dessa forma, o gênero feminino. O que a situação demonstra é que o gênero não tem nada de natural, mas necessita ser construído pelos atos performativos o tempo todo, pela ação dos outros sobre os corpos femininos e masculinos.

A performatividade de gênero não existe sem a presença dessas práticas forçadas $e$ proibitivas, mas que, ao mesmo tempo, são construtivas pela reiteração dos regimes sexuais reguladores incorporados pelos sujeitos (BUTLER, 2019). A mãe da criança coloca em circulação os regimes sexuais que regulam o que cabe ou não à menina, embaralhando o gênero com a sexualidade. Não estamos afirmando que esses atos performativos são conscientes; eles constituem a mãe como algo natural, eles formam o que essa mãe é, de maneira tão sutil, que não são problematizados. Podemos dizer que a mãe é resultado do mesmo processo que busca reproduzir na filha, o qual diz de um investimento que tem uma história. Os discursos performativos necessitam de autoridade, o que faz a mãe buscar, na escola e na professora, um "discurso de verdade" (FOUCAULT, 2006), convocando a escola, pela ação de confirmação da professora, a reiterar a separação entre o que é de menina e de menino.

Uma das manifestações de desigualdade entre mulheres e homens pode ser evidenciada nas distintas formas com que esses sujeitos, desde a infância, recebem a educação familiar e escolar: as mulheres sendo ensinadas a servir e agradar aos homens, demonstrando simplicidade e recato; e os homens convidados a trabalhar para sustentar a casa e a usufruir da beleza feminina (FELIPE, 2000). Dentro dessa lógica, as escolas também buscam "[...] manter uma severa vigilância em relação aos corpos infantis" (FELIPE, 2000, p. 128), tanto para eliminar qualquer forma de prazer e garantir uma certa "seriedade" na realização das tarefas escolares quanto para manter o controle 
e o disciplinamento dos corpos infantis. Contudo, vale destacar o entendimento de que a conduta feminina deve ser "muito mais severa" do que a masculina (FELIPE, 2000, p. 120).

Desde pequenas, as meninas são educadas a não ostentarem protagonismo. A atuação das mulheres deveria se dar sempre nos "bastidores". Mesmo sendo proclamadas como "sustentáculos do lar" e também da nação, deveriam ficar escondidas, uma vez que a visibilidade era uma prerrogativa masculina (SUBIRATS apud FELIPE, 2000, p. 120).

Os brinquedos também dizem desse protagonismo negado às mulheres e reservados aos homens. Em uma das atividades que realizamos nas escolas, perguntamos: Quais brinquedos são dados a bebês meninas? As respostas foram as seguintes: bonecas, roupas e objetos da cor rosa, bichinhos de pelúcia, panelinhas. Em relação aos bebês meninos, as respostas variaram: carrinhos, bolas, camisa de futebol etc. Para as meninas, os brinquedos que são comumente destinados ao espaço doméstico e com pouca ou nenhuma ação e aventura. Para os meninos, os brinquedos exigem ação no espaço público. Vamos ensinando, desde a infância, que o espaço público é dos homens e o espaço privado reservado às meninas. Diferenças que vamos reproduzindo sem nos darmos conta e, quando encontramos uma menina que quer um carrinho, isso se torna um "problema", exige um controle e uma ação dos pais para "corrigir" esse desejo.

Com isso, queremos dizer que a ação da mãe está ancorada em um conhecimento, em uma forma de conhecer e de saber dos gêneros que organiza a sua ação e a sua existência como mãe e como mulher. A questão é que ela cobra isso da escola, revelando um sentido de escola que a constitui como uma instituição que tem esse papel de vigiar, controlar e disciplinar as crianças. Alfredo Veiga Neto (2003) nos convida a colocar sob investigação essas relações entre a escola que temos hoje e a sociedade para, "[...] em vez de pensar que já sabemos o que é a escola" (VEIGANETO, 2003, p. 104), o interessante seria “[...] examinar como ela se tornou o que é, como ela está envolvida com a sociedade em que se insere, como podemos entender melhor, através dela, as transformações que o mundo está sofrendo"(VEIGA-NETO, 2003, p. 104). Mas, sendo a escola um espaço diferente, que deve "fazer a diferença" na constituição dos sujeitos, isso faz com que a instituição não tenha compromisso com o saber do senso comum. Ao contrário disso, deve ter o compromisso com os conhecimentos científicos.

Como nos mostra Foucault (2006), há uma história do pensamento que nos organiza e da qual somos herdeiros. A fala e a ação da mãe dizem dessa história do pensamento que destinava às mulheres esses atributos de docilidade. Havia, inclusive, desde o século XVIII, uma preocupação com a educação moral das crianças. Contudo, como podemos observar, havia um direcionamento sexista em relação à conduta das meninas e dos meninos. Em relação às meninas e às mulheres, notava-se uma preocupação muito maior em relação à definição dos comportamentos considerados adequados, corretos, dignos e decentes. Em contrapartida, meninos e homens eram "[...] colocados quase sempre como o centro das atenções", e a masculinidade era constantemente "alvo de preocupação", sendo os homens também ensinados a "seduzir" as mulheres (LOURO, 2000).

Conforme aponta Parker (1999), a sociedade brasileira tratou a feminilidade como uma "força natural" a ser controlada e disciplinada, enquanto a masculinidade deveria ser "cultivada" e apoiada desde a primeira infância. A educação do menino deveria direcioná-lo a atividades concretas de trabalho fora de casa e a educação das meninas deveria ensiná-las a sempre estarem ocupadas com a casa, com os filhos e com o marido (FELIPE, 2000). Toda e qualquer ameaça ao rompimento das fronteiras de gênero e/ou sexuais apontaria, portanto, para uma anormalidade ou patologia (FOUCAULT, 1988). Daí a preocupação exacerbada em relação aos programas 
educacionais da época no sentido de divulgar uma certa "moralidade compulsória", que garantisse a docilização e a conformação dos corpos mais tarde. Daí a preocupação da mãe com o pedido e desejo da filha e a busca, na escola, de reforçar o investimento na docilidade das meninas.

Dizer que a história do pensamento organiza nossas ações não significa ficar nessa história, mas, sim, tomá-la como ponto de problematização pensando que a história é feita por descontinuidades e rupturas. A escola não tem compromisso com a reprodução dessa história que constrói as desigualdades entre meninas e meninos. A situação narrada pela professora recupera aqueles dois movimentos que nos motivou para a escrita deste artigo e que foram evidenciados na introdução, ou seja, um conhecimento que atribui ao gênero uma naturalização, algo que também foi reiterado pelas famílias, em contraponto com o conhecimento que entende gênero como construção e resultado da relação saber-poder.

É a coexistência dessas duas formas de saber que dão vida à tensão da professora, que, conquanto pareça entender que o caminho não é reafirmar que carrinho é coisa de menino, não encontra armas para argumentar no caminho mais libertador dos gêneros. Uma situação que nos conduz ao questionamento sobre a força das nossas produções teóricas no campo das relações de gênero e da sexualidade e o desafio de fazê-las chegar às escolas, de não somente reconhecer que as desigualdades entre meninas e meninos se dá no campo social e cultural, mas também como uma tentativa de romper com essa produção. É o mesmo tipo de provocação que Foucault faz quando argumenta que a questão é "[...] saber de que modo, em uma sociedade como a nossa, é possível haver essa produção teórica, essa produção especulativa, essa produção analítica sobre a sexualidade no plano cultural geral e, ao mesmo tempo, um desconhecimento do sujeito a respeito de sua sexualidade" (FOUCAULT, 2006, p. 59).

Outra questão relacionada à desigualdade é a ideia de que a distinção entre mulheres e homens ocorreria fundamentalmente em função das características biológicas capazes de distinguir um grupo de outro. Durante algum tempo, foi preciso, inclusive, que as pautas feministas reivindicassem alguns direitos, pautados na igualdade, na tentativa de refutar uma suposta superioridade masculina que lhes garantisse mais espaço e exercício de direitos na sociedade. Não foi em vão a luta pelo chamado "sufragismo universal", que tentava estender o direito ao voto às mulheres (LOURO, 1997). A partir daí, outras lutas fizeram pauta das reivindicações dos movimentos feministas, dentre as quais destacamos a busca pela representatividade feminina na ciência e nas artes. Todavia, ainda hoje, busca-se construir um "olhar mais feminino" acerca dos fenômenos sociais e culturais, mostrando que a segregação das mulheres, ao longo da história, produziu "[...] a sua ampla invisibilidade como sujeito" (LOURO, 1997, p. 3). Invisibilidade esta que advém do fato de as mulheres terem passado grande parte do tempo na esfera do mundo doméstico, privado.

Por isso, reiteramos que, se a educação das crianças não começar por desconstruir tais desigualdades, dificilmente teremos adultas e adultos capazes de ocupar os mais diferentes espaços sociais, seja no âmbito público ou privado, o que manteria uma rígida divisão hierárquica entre os dois grupos - feminino e masculino.

\section{POR UMA RUPTURA DOS ENQUADRAMENTOS DE GÊNERO NA INFÂNCIA}

Quando somos convidados a estar junto a professoras em ações de formação na escola, um aspecto vem nos chamando atenção, que estamos chamando de uma "onda de casos", os quais vão surgindo a partir de uma primeira fala. Basta uma professora tomar a palavra e narrar um caso vivido no cotidiano escolar, para que outras surjam na mesma linha de contar o que viveram para organizar um "pedido de ajuda" para saber o que fazer. Também percebemos que há, nesses 
momentos, uma vontade de falar, demonstrando a importância desses momentos de formação para que as professoras possam trazer à tona as angústias e a tensão que estão presentes no dia-a-dia das escolas. Depois de narrada a situação da professora com a mãe e a filha, outras situações também foram surgindo, colocando-nos diante dos enquadramentos de gênero e os embaralhamentos com as sexualidades.

Eu tenho um problema... eu tenho um aluno que é gay... bom, eu acho que ele é gay. Ele só brinca com meninas, não gosta de jogar bola, gosta só de brincar de boneca e de casinha com as meninas. Quando estamos no cantinho da fantasia, ele só gosta de fantasiar de princesa. Ele não gosta de ir para o recreio, se eu deixar, ele só quer ficar desenhando e pintando... eu queria uma ajuda, como faço com ele?

Questionada sobre a idade do menino, a professora respondeu que teria 5 anos. O silêncio que a situação instaurou dizia sobre a receptividade das outras professoras, que pareciam já ter vivido situações semelhantes com as quais não sabiam lidar. Muitas vezes, a formação desperta esse sentido de que temos as respostas para tudo e que vamos solucionar os "problemas". No entanto, nossa função é colocar sob investigação nossas formas de saber, pensar e agir para que possamos modificá-las e propor outras maneiras de lidar com as situações entendidas como "problemas". Brincadeiras, roupas, adereços, materiais escolares, preferência por cores, formação de grupos, modos de ser e de falar... Tudo isso faz com que muitas pessoas criem uma distinção dicotômica e sexista, como se existissem "coisas de menina" e "coisas de menino", como faz a mãe diante da filha e da professora, assim como serve para classificar o menino como "gay". Uma pesquisa, realizada por Daniela Finco (2003), aponta que "[...] as crianças ainda não possuem práticas sexistas em suas brincadeiras" e que elas "[...] vão aprendendo a oposição e a hierarquia dos sexos ao longo do tempo" (FINCO, 2003, p. 95). Segundo a autora, são os/as adultas/os que esperam que as meninas sejam de um jeito e os meninos de outro. Isso nos leva a constatar que o preconceito de gênero é ensinado às crianças. Essa ação parte do outro, do adulto, que, no processo insistente de repetição, vai construindo e normatizando as diferenças entre o que é "ser menino" e o que é "ser menina”. Essa repetição das normas vai sendo incorporada até um ponto em que não há a necessidade do outro, como se fôssemos capazes de agir sobre nós mesmos através da repetição dessas normas em relação aos nossos corpos.

Nosso argumento aqui é o de que a escola participa desse projeto de ensinar sobre gênero, na medida em que nós, professoras e professores, aprendemos sobre o gênero, visto que as relações de gênero nos organizam. Nesse processo de construção das relações de gênero e sexualidade, estão em jogo as funções de "ensinar" e "aprender". Um jogo que vai definindo os modos de subjetivação no decorrer do processo educativo. Interessada nas discussões em torno do currículo como participante desse processo de "ensinar e aprender", Marlucy Paraíso (2016) vai demonstrar como os currículos vêm "ensinando sobre gênero" e como tudo isso tem "[...] dificultado o aprender na escola” (PARAÍSO, 2016, p. 208).

Entretanto, essa constatação não significa que o currículo e aquilo que acontece nas escolas se limitam à reprodução. Ao contrário disso, representa uma provocação para "[...] pensar possibilidades de 'desaprender' o já aprendido sobre gênero, abrindo os currículos para as 'subversões performáticas', para 'o falar das fronteiras' e para o 'conectar com a alegria"' (PARAISO, 2006, p. 208). Ao estabelecer a diferença entre "ensinar" e "aprender", a autora vai defender o currículo e a escola como um lugar de aprendizagem por excelência. Para a autora, "ensinar" está ligado às ações de "[...] transmitir, informar, ofertar, apresentar, expor e explicar 
conhecimentos e saberes pensados, pensáveis e aceitos" (PARAISO, 2006, p. 2009), enquanto "aprender", representaria "[...] abrir-se e refazer os corpos, agenciar atos criadores, refazer a vida, encontrar a diferença de cada um e seguir um caminho que ainda não foi percorrido" (PARAISO, 2006, p. 2009).

$\mathrm{Na}$ mesma linha de pensamento, Elizabeth Macedo (2012) vai afirmar que cabe aos currículos e à escola, na relação com os sujeitos, estabelecer a diferença entre "ensinar" e "educar", argumentando que a "[...] escola, para educar, precisa colocar o ensino sob suspeita" (MACEDO, 2012, p. 719). O que as duas autoras defendem nos interessa para pensar a relação entre ensinar, aprender e educar para as relações de gênero e para a sexualidade na educação infantil, visto que são duas posturas em favor da escola como espaço importante e necessário para romper com as desigualdades e os enquadramentos de gênero e sexualidade, entendendo que o projeto de educação envolve o domínio de conhecimentos socialmente produzidos, capazes de construir sujeitos críticos.

\begin{abstract}
Pois se gênero é construído, ele não é necessariamente construído por um "eu" ou um "nós" anteriores à construção em qualquer sentido espacial ou temporal desse "antes". Na verdade, não está claro se pode haver um "eu" ou um "nós" que não tenham sido submetidos, assujeitados ao gênero, se por atribuição de gênero entendemos, entre outras coisas, as relações de diferenciação pelas quais os sujeitos falantes vêm à existência. (BUTLER, 2019, p. 24).
\end{abstract}

Somos todos assujeitados ao gênero, porque gênero é o primeiro lugar de constituição dos sujeitos, como argumenta Judith Butler (2019). Dialogando com Michel Foucault, Butler também está interessada nos modos de subjetivação e em como as relações de gênero e sexualidade vão constituindo o que somos. No entanto, responder a pergunta - Como nos tornamos o que somos? - não significa permanecer no que somos, mas é uma aposta na mudança, uma aposta na liberdade dos sujeitos em fazer diferente. Tanto a mãe da criança quanto as professoras acionam relações de gênero que as subjetivaram. São essas relações que estão em jogo - ou de reprodução, como solicita a mãe; ou como possibilidade de alteração através do desejo de aprender da professora, quando nos coloca a situação num pedido de socorro sobre "o que fazer". Elas reconhecem que as crianças não incorporaram essas divisões entre os gêneros e entendem que seus papéis, como mãe ou como professora, são justamente de "ensinar" essas formas de lidar com o mundo e com os outros.

Assim como Daniela Finco (2003) afirmou que as crianças não possuíam, naturalmente, práticas sexistas nas brincadeiras e que essas práticas são construções culturais que vão sendo "ensinadas", o mesmo acontece com a constituição de grupos entre as crianças. Quando a/o adulta/o, representada/a pela figura da/o professora/or, não cria, na sala de aula, a divisão entre grupo de meninas e grupo de meninos (em trabalhos escolares, na formação das filas ou na separação dos banheiros, por exemplo), as próprias crianças "[...] criam novas formas de agrupamento" (FINCO, 2003), que, comumente, apresentam formas mistas - meninas e meninos participando juntas/os das mesmas atividades. Novamente, a autora afirma que "[...] os estereótipos dos papéis sexuais, os comportamentos pré-determinados, os preconceitos e discriminações são construções culturais, que existem nas relações dos adultos" (FINCO, 2003, p. 95).

Tal entendimento pode também ser observado na distinção das vestimentas. As vestimentas infantis estão seriamente demarcadas pela cor (azul ou rosa) e também pelas personagens dos desenhos animados e filmes infantis (MEIRELES, 2018, p. 124). A demarcação das roupas serve tanto para a construção do gênero quanto para as sexualidades, uma vez que se 
vestir de princesa é o suficiente para que a professora classifique e enquadre o menino como gay. Onde está o gênero e a sexualidade: na cabeça da professora ou no menino? Ainda mais complicado é o fato de que, a partir dessas demarcações, sejam feitos julgamentos e suposições acerca da sexualidade (ou orientação sexual) das crianças. Agravando ainda mais a condição de liberdade desses sujeitos, passa-se a afirmar que aquelas/es que não se enquadrarem em tais estereótipos devem ser (ou podem se tornar) homossexuais (GOELLNER, 2012).

No Brasil, mais do que relações de gênero e sexualidade, podemos dizer que há um certo embaralhamento entre gênero e sexualidade. Comumente, lidamos com as definições de gênero como se houvesse uma fronteira entre o que cabe a meninas e meninos ou entre o que pode e o que não pode para meninas e meninos, quase não havendo grandes problemas quando cada um fica no seu lado da fronteira.

O problema parece surgir quando o menino se aproxima do que é próprio de meninas ou quando a menina se aproxima do que é tido como próprio de meninos, como aconteceu nas situações narradas pelas professoras. Nessa aproximação da fronteira, o medo que se instaura é o resultado desse embaralhamento entre gênero e sexualidade, visto que, para ser mulher ou homem, há a necessidade de ser heterossexual. A heterossexualidade parece confirmar o gênero e, por outro lado, as homossexualidades parecem expulsar a menina do gênero feminino, assim como o menino do gênero masculino. O enquadramento ao gênero pressupõe, pois, o enquadramento a uma "sexualidade normativa". Como vivemos em uma sociedade heteronormativa, quando as crianças se distanciam desse enquadramento gênero/heteronormatividade, estabelece-se um outro enquadramento pela sexualidade, de maneira que a menina ou o menino se transforma na lésbica ou no homossexual, respectivamente, num processo de absolutização das identidades no qual a menina deixa de ser a boa filha, a boa aluna, a boa amiga, para ser a lésbica. Assim, a identidade sexual "canibaliza as outras identidades".

Dessa forma, gostar de blusa azul e que não seja curta ou apertada, sendo menina, passa a ser uma afronta ao gênero feminino; gostar de rosa e se recusar a gostar de carrinho, luta ou superheróis, sendo menino, transforma-se em probabilidade de que sua masculinidade seja contestada. Conforme destaca Felipe (2007, p. 84), é importante observar que essas construções "[...] pautadas na ideia de 'essência' ou 'natureza' são ainda hoje muito veiculadas, na tentativa de justificar todo e qualquer comportamento relacionado às masculinidades e às feminilidades". No entanto, cabe-nos defender que a escola, enquanto espaço de formação e produção cidadã, deve, sim, afastar das crianças essas condutas e modos de comportamento que se diferenciam pelo sexo/gênero, para que elas deixem de ser consideradas naturais ou adequadas (LOURO, 1997).

Não cabe mais, no contexto da educação, continuar ouvindo afirmações ou indagações como: "Essa cor é de mulher"; "Homem usa brinco?"; "Fulana está parecendo homem"; "Fulano é mulherzinha". Essas falas vieram de crianças da educação infantil e foram registradas em uma pesquisa (MEIRELES, 2008), que mostrou que as crianças comumente modificam suas concepções diante das problematizações de gênero feitas pela/o adulta/o (na figura da/o professora/or). Daí a importância de essas/es profissionais, que atuam "ensinando", ajam também "educando" não para a confirmação de certos discursos preconceituosos e sexistas, mas para mostrar às crianças que existe uma infinidade de modos de "ser menina" e de "ser menino", que, mesmo não sendo contemplados nas formações discursivas que as crianças trazem, por intermédio da família, devem sim ser reconsiderados ou, como afirma Macedo (2012), colocados sob suspeita.

Ao pressupor uma rigidez na diferenciação por gênero, muitas/os professoras e professores acreditam ser difícil questionar tais construções, porque imaginam que, se assim o fizessem, sofreriam retaliações da direção da escola ou das famílias das/os alunas/os. Contudo, cabe-nos aqui refletir sobre o projeto de educação que queremos construir com as nossas crianças, para que 
elas sejam libertadas dessa armadilha que é buscar ser o que os outros querem que elas sejam e não quem elas são de verdade.

Nessas nossas idas às escolas, temos percebido que uma das grandes dificuldades é lidar com a outridade das alunas e alunos, com aquilo que as alunas e alunos querem ser e não o que as professoras querem que sejam, vez que nossas escolas estão vinculadas ao projeto de uma sociedade disciplinar. Essa não é uma questão exclusiva das professoras, mas uma dificuldade também dos pais e responsáveis. Isso porque as escolas, desde a modernidade, estão diretamente ligadas ao projeto de construir um tipo de mundo ligado à ordem, à disciplina e à vida civilizada. (VEIGANETO, 2003). Esse projeto não é colocado em vigor, unicamente, pelas escolas, envolvendo a pressão das famílias. A possibilidade de ter filho aciona valores nas pessoas, de maneira que os pais acabam projetando nas filhas e filhos o que são seus valores. Assim, garantir que esses valores se tornem realidade é entendido como sua função no processo educativo de conduzir suas filhas e seus filhos para essa vida civilizada e em ordem. Ter filha ou filho parece ser uma vontade de vencer a morte, de se ver perpetuado nos seus descendentes, de ver passados para elas e eles os seus valores. A possibilidade de filhas e filhos terem valores diferentes é um dos grandes medos dos pais. Nesse sentido, as relações de gênero e sexualidade estão nesse campo de atuação e investimento na continuidade. Talvez esse seja o grande desafio para as escolas, ou seja, olhar as alunas e alunos por suas outridades e não por aquilo que queremos que elas e eles sejam. Compreender aquilo que se é ou como nos tornamos quem somos, é um apelo de Silvio Gallo (2003), embasado em Gilles Deleuze e compartilhado por nós, numa tentativa de produzir novos sujeitos. Para formar novos sujeitos, sem as amarras do gênero e da sexualidade, é preciso também criar novas formas de "educar".

Partindo desse raciocínio, Ribeiro (2012, p. 7) nos convida a "[...] mobilizar a escola e a incluir o gênero e a sexualidade nos currículos e, decisivamente, inventar formas diferentes de abordá-los". No que tange à educação infantil, essa necessidade se torna ainda maior, visto que, em razão de se considerarem gênero e sexualidade como conceitos idênticos, nega-se a possibilidade de se trabalhar de forma direta e incisiva o tema das relações de gênero com as crianças, sob o peso de incitá-las a desenvolver precocemente as suas sexualidades. Está aqui um aspecto importante: conhecer as conceituações e as teorizações de gênero antes de criticá-las sem qualquer fundamento.

\section{CONSIDERAÇÕES FINAIS}

Gostaríamos de trazer aqui alguns encaminhamentos que possam conduzir as professoras e os professores na educação para o gênero e para a sexualidade desde a educação infantil, contribuindo para o trabalho coletivo e para colocar sob suspeita as formas de conhecer que organizam as ações, as tensões, as inciativas, as curiosidades das professoras e professores, quando se deparam com algum fato que exige o trabalho com as relações de gênero e sexualidade nas escolas.

O primeiro deles remete à necessidade exposta neste artigo de a escola e, junto dela, as professoras e professores compreenderem que filiação adotam em relação aos conceitos de gênero e de sexualidade, de modo a terem clareza sobre seus significados, não mais restritos a uma conformidade das crianças ao gênero ao órgão sexual de seu nascimento e, ao mesmo tempo, não configurando a sexualidade como ato genital, como se as formas de prazer estivessem restritas às genitálias das crianças. Nitidamente, o diálogo da mãe com a menina e a classificação precoce da homossexualidade do aluno, por nós relatados, ainda mantêm as formas rígidas das quais queremos escapar. Exploramos tais situações no sentido de chamar atenção para como o gênero e os embaralhamentos com as sexualidades não somente nos organizam, nos fazem olhar o mundo, 
mas também nos constituem. Nesse sentido, nossa defesa inicial é que um trabalho com as relações de gênero e sexualidades na educação infantil passa pelo trabalho de constituição de nós mesmos, professoras e professores nas nossas formas de olhar, entender e classificar os sujeitos. Nós somos uma sociedade do enquadramento. Isso significa que, nas nossas relações subjetivas, vamos enquadrando todas e todos que estão à nossa volta, sendo o de gênero um dos primeiros enquadramentos que realizamos. A escola é parte dessa sociedade que enquadra, além de ser um campo que também produz esses enquadramentos. Nosso artigo é um convite a pensar sobre os efeitos desses enquadramentos em nós mesmos, como professoras e professores, e no que fazemos com eles, como vamos agindo sobre as alunas e alunos a partir daquilo que nos constitui. Esse convite se desdobra em outro que é o convite para ampliar as possibilidades de existências e de vivências das crianças.

O segundo refere-se ao cuidado que as/os profissionais da educação precisam ter em relação ao compromisso com a "educação" que oferecem às crianças, de modo a não conformálas a um repertório específico de características, comportamentos, hábitos ou atitudes simplesmente por "pertencerem" a um ou outro gênero. Isso se evidenciou na conversa da mãe com a professora, quase em um tom de exigência, para que confirmasse seus pressupostos rígidos, mas, sobretudo, na preocupação com a homossexualidade do aluno advinda de um comportamento não entendido como próprio do gênero masculino. Entende-se, para isso, que a educação seja muito mais do que um processo de transferir conhecimentos, envolvendo também os modos pelos quais produzimos os sujeitos infantis para atuar no mundo. Assim, acreditamos que o trabalho com as relações de gênero e sexualidade na educação infantil é sempre uma possibilidade de direcionar para a ampliação de experiências com brinquedos, brincadeiras, cores, vestimentas, sem marcações e limitações de gênero, no sentido de propiciar masculinidades mais sensíveis, menos violentas, como também feminilidades mais ativas e protagonistas. Hoje em dia as mulheres dirigem, trabalham fora, lutam pela diminuição da violência que sofrem e, mesmo assim, ainda temos problemas em dar carrinhos de presente para as crianças, mantendo brinquedos do ambiente doméstico. A educação, quando é problematizadora, é libertadora.

O terceiro e último ponto ressalta, assim, a necessidade de uma formação docente que esteja comprometida com o "desenquadramento do gênero" ou que, pelo menos, "desenrijeça" as formas brutas às quais geralmente buscamos adequar as nossas crianças. Essa foi a tentativa da menina ao relativizar o seu desejo de ter um carrinho, dizendo que ele poderia ser cor de rosa. Por tudo isso, buscamos produzir, junto a professoras e professores, uma experiência que "desembaralhe" ou "desvincule" os modos pelos quais esses sujeitos infantis se constituem no mundo dos modos pelos quais eles experimentam sua sexualidade. Não porque negamos a presença da sexualidade na infância, mas porque percebemos que o "casamento infeliz" desses modos de se produzirem como sujeitos mais atrapalha do que ajuda na instauração de práticas pedagógicas que revertam essa forma de casamento e construam novas parceiras, em um "casamento de sucesso".

\section{REFERÊNCIAS}

BUTLER, Judith. Deshacer el gênero. Barcelona: Paidos, 2006.

BUTLER, Judith. Corpos que importam. Os limites discursivos do "sexo". São Paulo: n-1 edições, 2019.

FELIPE, Jane. Infância, gênero e sexualidade. Educação \& Realidade, v. 25, n. 1, jan./jun., p. 115$131,2000$. 
FILHA, Constantina Xavier. Gênero, corpo e sexualidade nos livros para a infância. Educar em Revista, Curitiba, Ed. UFPR, Edição Especial n. 1/2014, p. 153-169.

FINCO, Daniela. Relações de gênero nas brincadeiras de meninos e meninas na educação infantil. Pro-Posições, v. 14, n. 3 (42), set./dez., 2003.

FOUCAULT, Michel. História da sexualidade I: a vontade de saber. 11. ed. Rio de Janeiro: Graal, 1988.

FOUCAULT, Michel. Ética, sexualidade, politica. Rio de Janeiro: Forense Universitária, 2006.

GALLO, Silvio. Deleure \& a Educação. Belo Horizonte: Autêntica, 2003.

GOELLNER, Silvana Vilodre. A importância do conhecimento histórico na formação de professores de educação física e a desconstrução da história singular. Kinesis, v. 30, n. 1, p. 37-55, jun. 2012.

LOURO, Guacira Lopes. Gênero, sexualidade e educação: uma perspectiva pós-estruturalista. Petrópolis, Rio de Janeiro: Vozes, 1997.

MACEDO, Elizabeth. Currículo e conhecimento: aproximações entre educação e ensino. Cadernos de Pesquisa, v. 42, n. 147, São Paulo, 2012.

MEIRELES, Gabriela Silveira. A infância nas tramas do poder: um estudo das relações entre as crianças na escola. Dissertação (Mestrado em Educação). Universidade Federal de Juiz de Fora, Faculdade de Educação. Juiz de Fora: EDUFJF, 2008.

MEIRELES, Gabriela Silveira. Um passeio pelo shopping em busca de... gênero e infância! Debates Insubmissos, Caruaru, Pernambuco, v. 1, n. 1, jan./abr. 2018.

PARAÍSO, Marlucy Alves. Currículo e relações de gênero: entre o que se ensina e o que se pode aprender. Revista Linhas, Florianópolis, v. 17, n. 33, p. 206-237, 2016.

PARKER, Richard. Cultura, economia política e construção social da sexualidade. In: LOURO, Guacira Lopes (org.). O corpo educado: pedagogias da sexualidade. Belo Horizonte: Autêntica, p. 125150, 1999.

RIBEIRO, Cláudia Maria. No labirinto da educação infantil as falas das educadoras sobre gênero e sexualidade. $35^{\circ}$ Reunião Nacional da ANPEd, 2012, Porto de Galinhas/Pernambuco. ANPEd, 2012.

SCOTT, Joan. Gênero: uma categoria útil de análise histórica. Educação \& Realidade, v. 20, n. 2, jul./dez., p. 71-99, 1995.

VEIGA-NETO, Alfredo. Pensar a escola como uma instituição que pelo menos garanta a manutenção das conquistas fundamentais da Modernidade. In: COSTA, Marisa Vorraber (org.). A escola tem futuro? Rio de Janeiro: DP\&A, 2003. 


\section{Informações do(a)(s) autor(a)(es)}

Anderson Ferrari

Universidade Federal de Juiz de Fora (UFJF)

E-mail: aferrari13@globo.com

ORCID: https://orcid.org/0000-0002-5681-0753

Link Lattes: http://lattes.cnpq.br/1349390714783997

Gabriela Silveira Meireles

Centro Universitário Governador Ozanam Coelho (UNIFAGOC)

E-mail: gabrielasilveirameireles@gmail.com

ORCID: https://orcid.org/0000-0002-9712-5488

Link Lattes: http://lattes.cnpq.br/7198043832595828 